\title{
The monocyte-macrophage-mast cell axis in dengue pathogenesis
}

\author{
Shu-Wen Wan ${ }^{1}$, Betty A. Wu-Hsieh², Yee-Shin Lin ${ }^{3,4}$, Wen-Yu Chen ${ }^{2}$, Yan Huang ${ }^{5}$ and Robert Anderson ${ }^{3,5,6^{*}}$ (D)
}

\begin{abstract}
Dengue virus, the causative agent of dengue disease which may have hemorrhagic complications, poses a global health threat. Among the numerous target cells for dengue virus in humans are monocytes, macrophages and mast cells which are important regulators of vascular integrity and which undergo dramatic cellular responses after infection by dengue virus. The strategic locations of these three cell types, inside blood vessels (monocytes) or outside blood vessels (macrophages and mast cells) allow them to respond to dengue virus infection with the production of both intracellular and secretory factors which affect virus replication, vascular permeability and/or leukocyte extravasation. Moreover, the expression of $\mathrm{Fc}$ receptors on the surface of monocytes, macrophages and mast cells makes them important target cells for antibody-enhanced dengue virus infection which is a major risk factor for severe dengue disease, involving hemorrhage. Collectively, these features of monocytes, macrophages and mast cells contribute to both beneficial and harmful responses of importance to understanding and controlling dengue infection and disease.
\end{abstract}

Keywords: Dengue pathogenesis, Mast cell, Monocyte, Macrophage, Vascular leakage

\section{Introduction}

Dengue is the most common mosquito-transmitted viral infectious disease, and therefore represents a major global health threat, especially in tropical and subtropical areas of the world. Over the past several decades, there has been an increase in dengue cases due to many factors, including increased air travel and climate change. It has been estimated that there are 390 million infections per year, of which 96 million cases show clinical manifestations [1]. Dengue virus (DENV) is a member of the Flavivirus genus of the Flaviviridae family and its genome is a single-stranded, positive-sense RNA, which encodes three structural proteins: envelope $(\mathrm{E})$, premembrane/membrane $(\mathrm{prM} / \mathrm{M})$ and capsid $(\mathrm{C})$ proteins, and seven nonstructural (NS) proteins [2]. There are at least four serotypes of DENV, all of which can cause disease. Most dengue patients present with dengue fever (DF) including fever, headache, bone pain and skin rash, but some may progress to life-threatening dengue hemorrhagic fever (DHF) or dengue shock syndrome (DSS) with major features of high levels of proinflammatory

\footnotetext{
* Correspondence: robert.anderson@dal.ca

${ }^{3}$ Department of Microbiology and Immunology, College of Medicine,

National Cheng Kung University, Tainan, Taiwan

${ }^{5}$ Department of Microbiology \& Immunology, Dalhousie University, Halifax,

NS B3H 4R2, Canada

Full list of author information is available at the end of the article
}

cytokines, vascular leakage, thrombocytopenia, hemorrhage, and hypotensive shock [3, 4]. There is still a demand for satisfactory vaccines and antiviral drugs. Although there is a licensed vaccine and several ongoing vaccine candidates in clinical trials, they confer only partial protection against DENV infection by some serotypes and may carry the risk of antibody-dependent enhancement (ADE) $[5,6]$. The difficulty of eliciting balanced efficacy of neutralizing antibodies against all four DENV serotypes remains a major concern.

Both innate and adaptive immune responses to DENV play significant roles in protection against DENV, but can also elicit pathological responses which may worsen disease $[2,7]$. Understanding the mechanisms that regulate immune-mediated protection versus pathogenesis is critical for the development of safe and effective dengue vaccines and therapeutic agents $[4,7]$. DENV can perturb vascular endothelium by multiple mechanisms, including vasoactive factors from intravascular cells such as monocytes and lymphocytes, and from extravascular cells such as mast cells and tissue macrophages. Various factors produced by $\mathrm{T}$ cells, monocytes, macrophages, and mast cells have been proposed to increase vascular permeability, including tumor necrosis factor (TNF), IL-1 $\beta$, IL-6, CXCL8 (IL-8), macrophage migration inhibitory factor (MIF), CCL2 (also known as monocyte chemoattractant protein-1,

(c) The Author(s). 2018 Open Access This article is distributed under the terms of the Creative Commons Attribution 4.0 International License (http://creativecommons.org/licenses/by/4.0/), which permits unrestricted use, distribution, and 
MCP-1), high mobility group box-1 (HMGB-1) and matrix metalloproteinases $[4,8]$.

Although DENV infects several cell types, monocytes, macrophages and mast cells are major responders to DENV infection by producing potent immunological mediators, including cytokines, chemokines, lipid-derived mediators and more. By virtue of cell surface expressed Fc receptors they can also function as major amplifiers of DENV infection in the presence of subneutralizing levels of antibody by the mechanism of ADE. In this review, we will focus on cells and cellular networks encompassing monocytes, macrophages, and mast cells that can uniquely amplify DENV infection by ADE and modulate pathogenesis by release of cytokines, chemokines, proteases and other factors.

\section{The monocyte-macrophage-mast cell axis}

Monocytes (and monocyte-derived cells including macrophages) as well as mast cells originate from bone marrow common myeloid progenitors (CMPs) by two distinct pathways. Monocytes differentiate from CMP-derived granulocyte/monocyte progenitors (GMPs) while mast cells develop from CMP- or GMP-derived mast cell progenitors (MCPs) which home to peripheral tissues where they progress to mature mast cells [9]. Mature mast cells, like their precursor MCPs, express the stem cell factor receptor CD117 (c-kit) and the high affinity FceR but differ from MCPs most notably by their high content of granules [10]. While monocytes remain largely in the circulation, monocyte-derived cells (including macrophages) as well as mast cells are resident in the tissues. All three cell types are potent producers of cytokines, chemokines and other factors some of which affect vascular integrity. Their locations either within or in close proximity to blood vessels as well as their potent innate immune responses to DENV infection allows them to function as an "axis" in regulating the fine balance between virus replication/suppression and disease.

\section{Monocytes and DENV}

Peripheral blood mononuclear cells, particularly monocytes have long been recognized as major targets of DENV infection and amplification [11-14], especially in the presence of low levels of dengue-specific antibody. The dramatic enhancement by dengue antibody of DENV replication in monocytes and certain other cells is known as ADE $[15,16]$. DENV comprises four serotypes (designated 1-4) against each of which the respective homotypic antiserum is much more effective than heterotypic antiserum in virus neutralization. ADE is hypothesized to contribute to heightened dengue disease severity and is believed to arise upon sequential infection of an individual with two different DENV serotypes in which antibody produced against the first serotype enhances infection of the second. The formation of virus-antibody complexes in such individuals gives rise to increased virus replication in cells bearing Fc receptors (eg. monocytes and a select number of other cells), triggering amplified virus- and immune-mediated pathogenic effects. In concordance with the ADE hypothesis is a study showing higher numbers of FcyRII bearing DENV-infected monocytes in DHF compared to DF patients [14]. Single nucleotide polymorphisms in the Fc $\gamma$ RII gene are also associated with altered susceptibility to severe dengue disease [17].

ADE of DENV infection has been differentiated into intrinsic and extrinsic components, denoting intra- and extracellular events respectively $[18,19]$. Extrinsic ADE is believed to result from increased virus binding and internalization via virus-antibody complex ligation of Fc receptors. Intrinsic ADE, which results from signaling through ligated FcRs, is postulated to suppress antiviral responses, selectively enhance cytokine production (particularly IL-10) and enhance virus replication [19]. Additional or alternative mechanisms may also be involved [20].

Infection of monocytes by DENV is dependent on monocyte phenotype, as defined by relative expression levels of certain protein markers which are associated with differentiation or activation status [14, 21, 22]. Human monocytes are in fact a heterogeneous population which can be grouped into at least three subsets [23, 24]. One study found DENV infection predominantly in one subset of monocytes expressing CD14, CD32, CD86 and CD11c [14]. Another study reported upregulation of CD14 and CD16 in DENV-infected blood monocytes which mediate $B$ cell to plasmablast differentiation and production of IgM and IgG [22]. However, another study reported no increase in blood $\mathrm{CD} 14^{+} \mathrm{CD} 16^{+}$monocytes [25]. A correlation between DENV-induced monocyte activation and severity of disease has been reported [14].

DENV infection of monocytes triggers the release of numerous immunological factors, some of which modulate the function of other cells, particularly vascular endothelial cells. Endothelial cells are activated by TNF released by antibody-enhanced DENV-infected monocytes [26]. Circulating TNF levels are altered in severely afflicted dengue patients [27-29] and TNF is a crucial factor in DENV-induced hemorrhage in a mouse model [30]. Moreover, human genetic studies of cytokine gene polymorphisms highlight a strong role for TNF in the severity of dengue disease [17].

In addition to TNF, other monocyte-secreted factors can prime or trigger endothelial cell permeability leading to vascular leakage, a major hallmark of severe dengue disease. Other cells including lymphocytes and endothelial cells themselves can further contribute to vascular leakage via the secretion of similar or other vasoactive factors. Which of these factors predominate in triggering dengue-associated endothelial permeability is widely 
debated, but likely candidates include vascular endothelial growth factor (VEGF), platelet activating factor (PAF), leukotrienes, matrix metalloproteinase-9 (MMP-9), sphingosine-1-phosphate (S1P), DENV NS1 protein (reviewed in [8]) as well as MIF [31] and glycosaminoglycans such as hyaluronic acid and heparan sulfate [32]. The dominant source(s) of these factors awaits definitive identification, but likely includes monocytes, lymphocytes, endothelial cells and platelets. Platelets, which have been shown to undergo marked changes in protein expression during dengue infection [33], may also enhance cyto/chemokine production by DENV-infected monocytes through a contact-dependent mechanism [34].

A picture of complex cellular interplay during dengue infection is beginning to emerge. For example, dengueinfected monocyte-derived dendritic cells are able to activate natural killer (NK) cells which in turn may suppress DENV infection of monocytes by a mechanism involving interferon (IFN) $-\gamma$ [35]. DENV replication in monocytes may also be suppressed by NK cell activation through a TRAIL-dependent mechanism augmented by type I IFNs [36]. On the other hand, monocyte-derived dermal macrophages bind and internalize DENV into early phagosomes but do not permit virus replication and may therefore have a role in sequestration and early control of the virus. Such DENV-exposed dermal macrophages apparently do not produce IFN- $\alpha$ [37] and therefore likely restrict virus replication in themselves without conferring antiviral resistance on other cells.

Monocyte-derived cells do not always have a protective role in DENV infection. In the mouse model, monocytes which migrate to the virus inoculation site in the dermis and differentiate into dendritic cells may become fresh targets for virus replication in the skin [38, 39].

It is important to note that DENV-induced cellular (including monocytic) infiltration into the skin is not generalized, but rather is restricted to the site of virus inoculation as indicated by studies on mice $[38,39]$ as well as cynomolgus macaques [25]. Although limited, studies on humans also indicate a lack of widespread cellular infiltration into skin even in patients showing severe dengue disease, i.e. DSS [25].

Monocytes and monocyte-derived cells therefore play seemingly synergistic as well as opposing roles in dengue disease. In addition to their important beneficial role in virus clearance by activating $\mathrm{T}$ cells in the draining lymph node [40], they may also contribute either negatively or positively to virus replication in the skin.

\section{Role of apoptosis in DENV-monocyte interactions}

Apoptosis of peripheral blood mononuclear cells (PBMCs), including lymphocytes and monocytes as well as phagocytic engulfment of apoptotic cells were noted in children with acute DENV infection [41]. Such apoptosis was proposed to represent a modulating mechanism for both virus replication as well as cell-mediated immune responses [41]. Apoptosis has also been observed in DENV-infected monocyte and/or macrophage cultures [42-46]. Multiple mechanisms of apoptosis induction have been proposed including components of both the intrinsic and extrinsic pathways. Caspase- 8 activation and concomitant TNF production has been reported in DENV-infected monocyte-like U937 cells [43]. Caspase-1 has been implicated in both IL-1 $\beta$ production and pyroptosis in DENV-infected monocytes [47]. IL- $1 \beta$ is a known activator of endothelial cells and, along with monocyte-produced TNF [26], could contribute to vascular permeability in dengue disease.

\section{Macrophages and DENV}

Jessie et al. [48] identified DENV antigen and RNA in macrophages, multinucleated and reactive lymphoid cells in the spleen, Kupffer cells and sinusoid endothelial cells of liver, and macrophages and endothelial cells in the lungs of human autopsied and biopsied samples. Balsitis et al. [49] identified DENV NS3 protein in phagocytes of spleen and lymph nodes, in alveolar macrophages in the lungs, and in perivascular cells in the brains from dengue autopsy cases. An in vitro study also showed that primary human peripheral monocytes and splenic macrophages are permissive for DENV [50]. The mannose receptor on primary human macrophages that binds to the envelope protein of DENV through its carbohydrate-recognition domain may be responsible for recognition and uptake of the virus [51]. The observation that IL- 4 treatment renders human dermal macrophages and dendritic cells isolated from healthy human abdominal skin permissive to DENV infection [52] could be the result of upregulation of the mannose receptor on macrophages by IL-4 [53].

In Stat1 $^{-/-}$mice infected with DENV, Chen et al. identified CLEC5A as a receptor for DENV [54]. Blocking CLEC5A protected mice from DENV-induced pathology and death [54]. CLEC5A has also been identified as the receptor that mediates DENV-induced IL- $1 \beta$ on GM-CSF-stimulated human monocyte-derived macrophages [55].

In AG129 mice infected subcutaneously with DENV2 (PL046 or mouse-adapted D2S10), viral E and NS1 proteins are detected in $\mathrm{F} 4 / 80^{+} \mathrm{CD} 11 \mathrm{~b}^{+}$macrophages and $\mathrm{CD}_{11 \mathrm{c}^{+}}$dendritic cells in the spleen and other lymphoid tissues during the early phase of infection [56]. By inoculation of labeled DENV intravenously to AG129 mice, Prestwood et al. [57] found that macrophages, initially in lymphoid tissues, especially in the spleen, are the main virus targets. In the later phase of infection, however, macrophages in non-lymphoid tissues also become targets of DENV replication. In wild-type mice infected by DENV2 through the intradermal route, both macrophages and endothelial cells are targets of the virus [30]. 
Macrophages are recruited to the vicinity of endothelium during hemorrhage development [58]. Their recruitment and response to the virus has a profound impact on the pathogenesis of hemorrhage [30].

\section{Cytokine production by macrophages in response to DENV}

Human monocyte-derived macrophages infected with DENV in vitro produce TNF, IFN- $\alpha$, IL-1 $\beta$, CXCL8 (IL-8), IL-12, CCL3 (MIP-1 $\alpha$ ) and CCL5 (Regulated on Activation Normal T cell Expressed and Secreted, RANTES) [12]. Autopsy tissues from dengue patients showed elevated levels of IFN- $\gamma$ and TNF expressing cells in livers, lungs and kidneys [59] and DENV RNA was detected in Kupffer cells producing these two cytokines [59]. The relationship between TNF and hemorrhage is worth noting. An early study in Thai children showed that plasma level of soluble TNF receptor (sTNFR) detected at $<72 \mathrm{~h}$ of fever is higher in children who developed DHF than those who had DF and TNF was detectable more often in children with DHF than with DF and children with fever from non-dengue-related illness [60]. TNF, which activates endothelial cells, is also produced by DENVinfected monocytes [26] and mast cells [61]. In a dengue hemorrhagic mouse model, skins obtained from hemorrhagic sites express higher levels of TNF transcripts and protein than that from non-hemorrhagic sites and TNF deficiency impedes DENV-induced hemorrhage development [30]. Immunofluorescence staining of hemorrhage tissues revealed that TNF co-localizes with macrophages and DENV infection of macrophages in vitro also induces TNF production [30]. These data demonstrate that TNF is important in severe dengue in humans as well as hemorrhage development in the mouse.

\section{Role of apoptosis in DENV-macrophage interactions}

Human liver Kupffer cells respond to DENV infection with cytokine production and apoptosis [62]. Although DENV replication is low or absent in cultured Kupffer cells [62], DENV antigen is detectable in Kupffer cells and hepatocytes in human autopsy studies [63]. Phagocytic Kupffer cells may also play a role in clearance of virus-induced apoptotic bodies in infected tissues [64].

Apoptosis is also observed in endothelial cells which are important targets of monocyte/macrophage action. Importantly, TNF and DENV-induced endothelial cell death resulted in alteration of endothelial permeability and pan-caspase treatment reversed its effect [58]. These results demonstrate that infection of endothelial cells by DENV in the presence of TNF changes endothelial permeability through caspase-dependent cell death. In the hemorrhage mouse model, hemorrhage development is accompanied by macrophage recruitment and endothelial cell death [58]. Macrophage production of TNF in the vicinity of endothelium that is infected with DENV may enhance endothelial cell death which contributes to hemorrhage development.

It is of interest to note that DENV NS2B/3 protease enzymatic activity is critical to DENV-induced endothelial cell death [65]. DENV NS2B/3 protease cleaves host

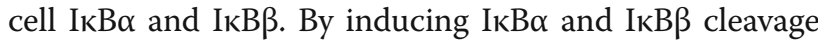
and IкB kinase activation, enabling p50 and p65 translocation to the nucleus, DENV NS2B/3 protease activates $\mathrm{NF}-\mathrm{kB}$ which results in endothelial cell death. Injecting DENV NS2B/3 protease packaged in adenovirus-associated virus-9 intradermally to mice induces macrophage infiltration, endothelial cell death and hemorrhage development [65]. Thus, the presence of TNF-producing macrophages near blood vessels contributes to DENV protease-induced endothelial cell death and hemorrhage development. A depiction of the possible events triggered by DENV infection that lead to hemorrhage development is shown in Fig. 1.

\section{Mast cells and DENV}

Mast cells are well known for their involvement in inflammation and allergy but recent studies indicate a broader role in immunological responses [66-69]. The abundance of mast cells at mucosal sites and skin confers on them a sentinel function for the early detection and disposition of invading pathogens. Upon appropriate stimulation, mast cells selectively produce and secrete a variety of mediators including chemokines, cytokines, lipid mediators and granule associated products. Mast cells reside mainly in the tissues and have been shown to associate closely with blood vessels [70] and nerves [71]. Human mast cells can express both FcERI [72, 73] and some $\mathrm{Fc} \gamma$ receptors including Fc $\gamma \mathrm{RI}[74,75]$ and FcyRII [76, 77] and contain FcyRIII mRNA [76].

Mast cells have aroused speculation for many years as to their possible involvement in dengue pathogenesis. Mast cells are located in the skin and mucosa which are the first line of defense against pathogens. In addition to dendritic cells (including Langerhans cells) and macrophages [78], mast cells also encounter DENV early in infection [79]. DHF patients exhibit increased levels of urinary and plasma histamine which is a major granuleassociated mediator from mast cells [80, 81]. Levels of mast cell-derived VEGF and proteases are also increased in DSS patients [82]. Furthermore, mast cell-derived chymase also promotes vascular leakage in a DENV-infected mouse model [83]. In vitro studies indicated that antibody-enhanced DENV infection of mast cells selectively induces production of chemokines including CCL3, CCL4 and CCL5 [84, 85], as well as cytokines including IL-6, IL- $1 \beta$ and TNF $[61,86]$. TNF produced from antibody-enhanced DENV infection of mast cells as well as of monocytes can trigger endothelial cell activation $[26,61]$. These findings suggest that mast cells 


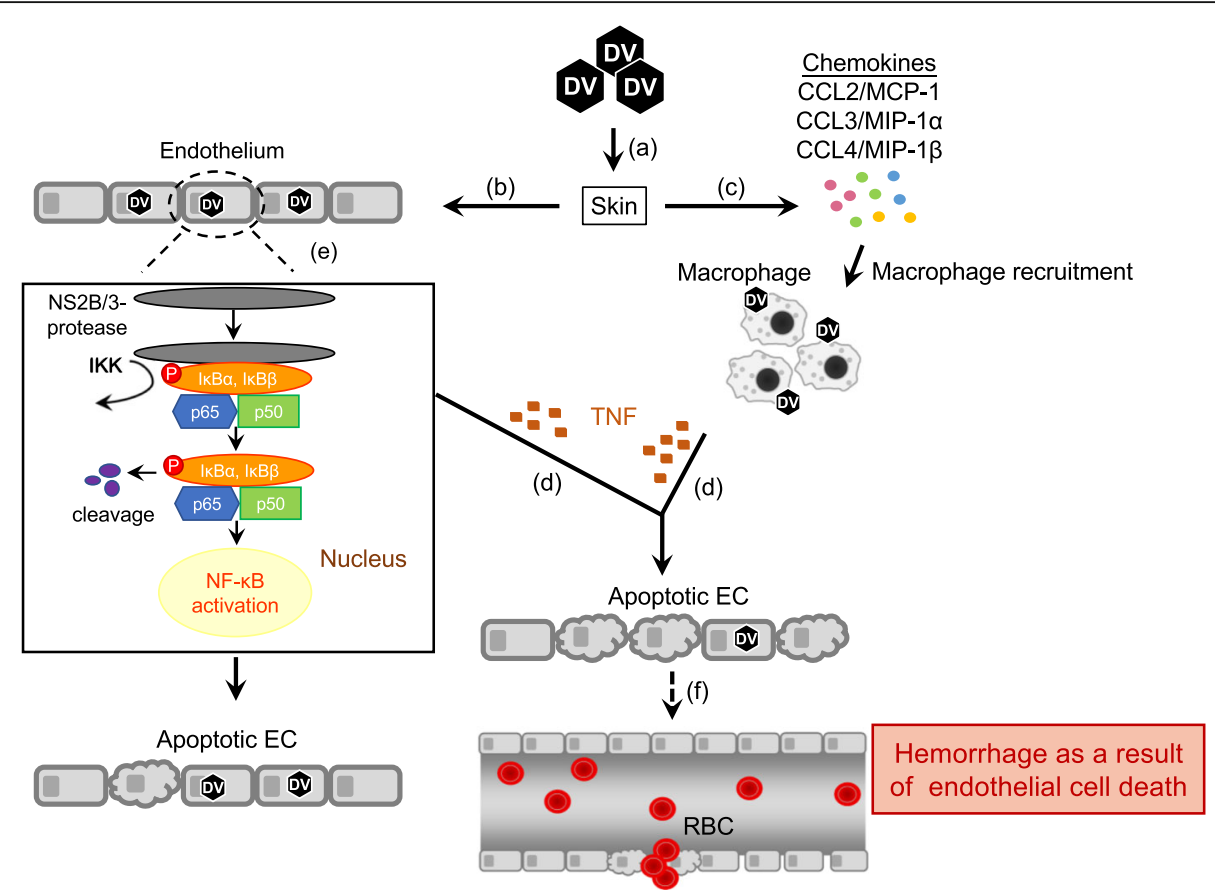

Fig. 1 Dengue virus interactions with macrophages and endothelial cells that lead to hemorrhage development. a Inoculation by mosquito bite of DENV (DV) into the skin. $\mathbf{b}$ The virus infects several cell types including endothelial cells (ECs). c DENV induces production of chemokines that attract macrophages. $\mathbf{d}$ DENV stimulates macrophages to produce TNF. e DENV NS2B/3 protease interacts with and cleaves cellular $1 \mathrm{kBa} / \mathrm{k} B \mathrm{~K}$. DENV NS2B/3 protease also activates IKK, which phosphorylates $1 \mathrm{kB}$ and $1 \mathrm{~KB} \beta$. IKBa/ $/ \mathrm{kB} \beta$ cleavage enables $\mathrm{p} 50$ and p65 translocation into the nucleus, thereby activating NF-KB which results in endothelial cell death. $\mathbf{f}$ The presence of TNF in the microenvironment enhances DENV-primed EC apoptosis. Endothelium damage/increased vascular permeability results in hemorrhage development. Solid arrows represent events that enhance endothelium damage. Dotted arrow indicates an event that is speculated to occur $[30,58,65]$

likely play a role in vascular function as well as leukocyte recruitment during DENV infection.

Most significantly, mast cells are susceptible to antibodyenhanced DENV infection via the mast cell FcyRII [87]. Mast cell responses to antibody-enhanced DENV infection have revealed potent immunoregulatory activities of these cells, including secretion of TNF [61] and the chemokines CCL3, CCL4 and CCL5 [84]. Together with other published reports $[67,68,88,89]$, these studies reinforce the role of mast cells as innate immune effectors in response to a variety of virus infections. Chemokines such as CCL3, CCL4 and CCL5 are important for the trafficking of leukocytes such as monocytes, T cells, and NK cells, all of which are suggested to play important roles in dengue infection. Serum levels of CCL3, CCL4 and CCL5 are altered [90-93] and tissue levels of chemokine-producing cells are elevated $[59,93]$ in dengue patients. In particular, serum levels of CCL4 are increased in mild dengue and may be of good prognostic value [93].

\section{Induction of innate immune factors in DENV-infected mast cells}

The cellular molecules by which DENV is detected by the innate immune system have been partly characterized. RIG-I or MDA5 have been implicated in the production of
CCL 5 and CXCL8 by a number of viruses, including DENV as well as viral RNA homologs $[85,94,95]$. Upregulation of RIG-I and MDA5 mRNA has been demonstrated after DENV infection in a rodent mast cell line [79] as well as antibody-enhanced DENV infection of human mast cells [85]. Protein kinase dsRNA dependent (PKR) recognizes dsRNA and can mediate the inhibition of protein translation in response to type I IFNs and DENV dsRNA [96]. Together, all three RNA sensors provide a mechanism by which the innate immune system induces the antiviral response when the host is exposed to DENV.

In addition to the above-noted RNA sensors RIG-I, MDA5 and PKR, mast cells possess a battery of pattern recognition receptors the individual expression of which varies according to the host source and associated tissue or organ [97-100]. Human mast cells express the RNA sensor, Toll-like receptor (TLR)3 [89]. Recognition of viral dsRNA by mast cell TLR3 leads to signaling via TRIF to TBK1/IKKe to activate both IRF-3 and nuclear factor- $\kappa B(N F-\kappa B)$ promoting the production of IFN stimulated genes, cytokines and chemokines. In the case of human mast cell lines HMC-1 and LAD-2 as well as primary peripheral $\mathrm{CD} 34^{+}$mast cells, responses to extracellular polyinosinic polycytidylic (polyI:C) were shown to involve upregulation of type I IFNs by RT-PCR [89]. 
Mast cells activated by polyI:C have also been reported to influence $\mathrm{CD}^{+} \mathrm{T}$ cell recruitment [88]. Furthermore, polyI:C-exposed or reovirus-infected mast cells recruit NK cells in a CXCL8-dependent manner [101]. Along with other RNA sensors, TLR3 is also upregulated in antibody-enhanced DENV infection of mast cells [85].

Antibody-enhanced DENV-infected mast cells can produce sufficient amounts of type I IFNs to protect neighboring cells from infection [85]. The upregulation of RNA sensors such as RIG-I and MDA5 appears to be key for the suppression of DENV replication via establishment of the antiviral state [102-104]. The upregulation of PKR in mast cells upon antibody-enhanced DENV infection [85], is also consistent with induction of the antiviral state since protein translation inhibition during DENV infection is dependent on the PKR substrate, eIF2 $\alpha$ [96]. The possibility that tissue-resident mast cells can initiate this vital response would therefore allow them to confer type I IFN-mediated protection upon neighboring cells at the tissue site early after virus inoculation.

\section{Roles of mast cells in DENV clearance and vascular leakage}

After DENV infection, mast cell-deficient mice showed increased viral burden within draining lymph nodes, compared with wild-type mice. In addition, the recruitment of
NK and NKT cells into the DENV-infected skin was dependent on mast cell activation [79]. Such mast celldependent immune responses facilitate DENV clearance. Compared to wild-type mice, mast cell-deficient mice showed enhanced DENV infection, CCL2 production and macrophage infiltration at the skin inoculation site, suggesting other mechanisms for the interplay between mast cells and tissue macrophages to modulate DENV replication [105]. Therefore, during the initial stage, mast cells may play crucial roles in immune surveillance for DENV by promoting viral clearance and restricting viral replication (Fig. 2).

Several mast cell-derived mediators, such as tryptase, chymase and VEGF contribute to dengue disease severity [82]. Serum chymase levels could be a predictive biomarker of DHF in pediatric and adult patients [106]. DENV-infected mice show activated degranulated tissue mast cells. as well as elevated systemic levels of various vasoactive products, including chymase, histamine, and serotonin [83]. After DENV infection, mast cell-deficient mice showed significantly reduced vascular permeability compared to mast cell-sufficient controls [83]. Hence, at later stages of systemic infection, mast cells might play other important roles in DENV-induced vascular leakage (Fig. 2). Sub-neutralizing dengue-specific antibodies not only promote DENV infection but also enhance mast cell

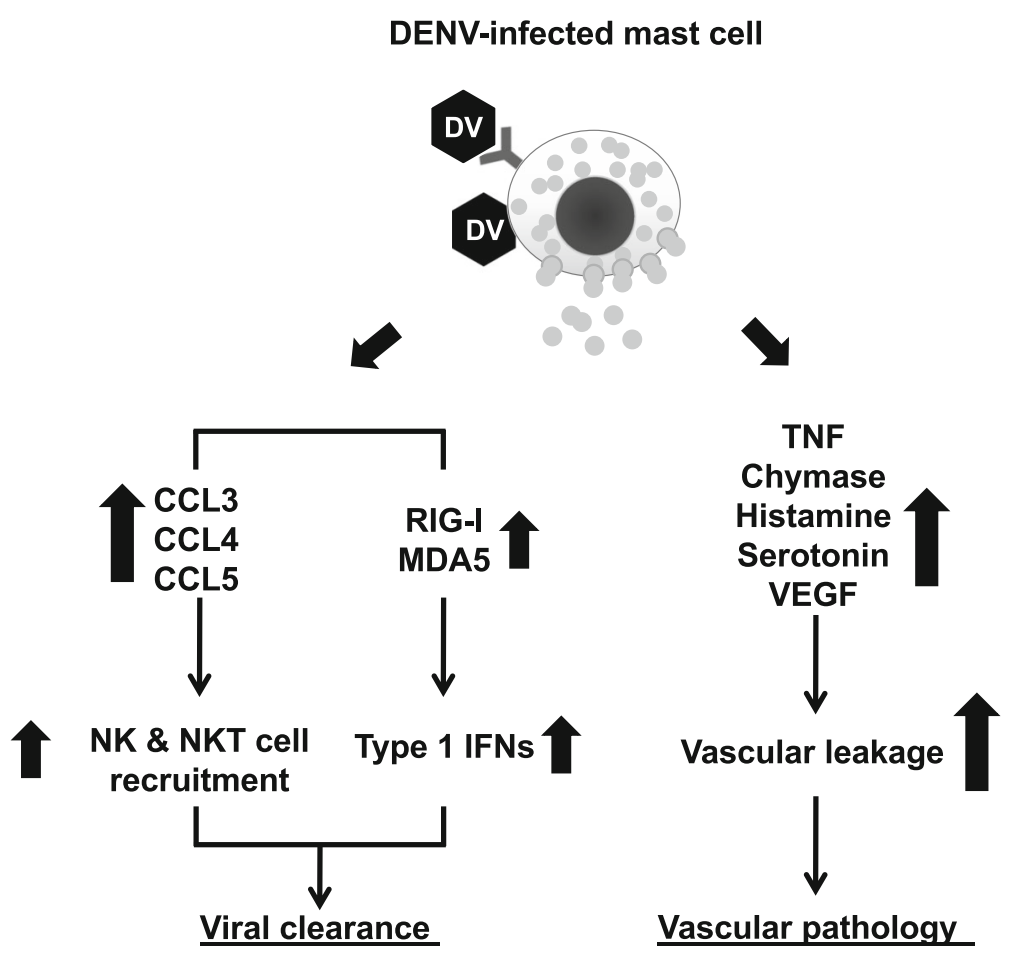

Fig. 2 The dual roles of mast cells in dengue infection. Mast cells respond to DENV (DV) infection via RNA sensors (RIG-I and MDA5) which are involved in type I IFN production to inhibit viral replication. DENV-infected mast cells also secrete chemokines including CCL3, CCL4 and CCL5, which recruit NK and NKT cells to help clear the virus. However, if initial control mechanisms fail, the virus may spread to other organs. DENV-infected mast cells in these organs secrete vasoactive products, including TNF, chymase, histamine, and serotonin and VEGF which contribute to vascular permeability 


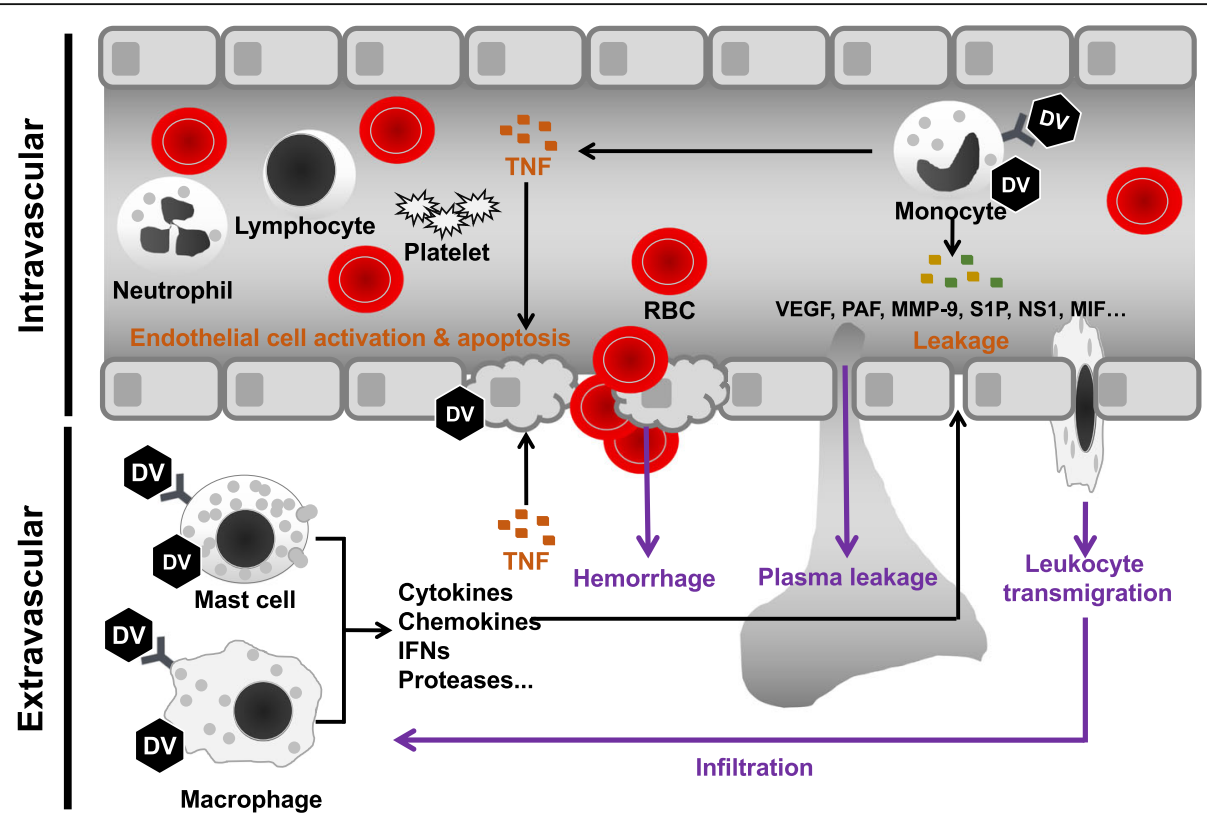

Fig. 3 Intra- and extravascular cells in the pathogenesis of dengue. DENV (DV) infection of monocytes triggers the intravascular release of numerous immunological factors to modulate the function of vascular endothelial cells. Besides TNF, other monocyte-secreted factors can prime or trigger endothelial cell permeability leading to vascular leakage and leukocyte transmigration to extravascular tissues. Extravascular mast cells and macrophages are target cells for DENV infection which elicits production of cytokines, chemokines, lipid-derived mediators and proteases which also contribute to endothelial cell permeability. In addition, macrophage production of TNF enhances DENV-infected endothelial cell death which leads to hemorrhage development

activation in an FcyR-dependent manner [87, 107]. During secondary DENV infection, antibody-mediated mast cell activation may therefore also contribute to the enhanced vascular pathology in severe dengue (Fig. 3).

The involvement of mast cells in dengue pathogenesis suggests they may be potential therapeutic targets. The mast cell-stabilizing drug, ketotifen, not only improves DENV-induced vasculopathy [83] but also reverses the DENV-induced host response without suppressing memory T cell formation [108]. Furthermore, antibodies against DENV NS1 provide protection in mice against DENV challenge and reduce mast cell degranulation and macrophage infiltration as well as the production of chemokines including CCL2, CCL5, and CXCL10 (IP-10) at local skin DENV infection sites [109].

\section{Role of apoptosis in DENV-mast cell interactions}

Antibody-enhanced DENV-infected mast cell-like KU812 cells show dramatic apoptosis [110]. Interestingly, apoptosis is observed mainly in DENV antigen-negative cells suggesting the involvement of apoptotic mediators produced by DENV-infected cells. Alternatively, apoptosis may be triggered very early in some DENV-infected cells so that cell death occurs prior to appreciable virus replication. Thus, as with monocytes and macrophages, apoptosis of mast cells in DENV infection likely plays a role in regulating mast cell numbers and responses.

\section{Conclusions}

While differing in cellular developmental pathways, monocytes/macrophages and mast cells share intriguing features which come into play in vascular disease triggered by DENV infection. Their potent production of cytokines, chemokines and various vasoactive mediators in response to DENV makes them key orchestrators of some of the pathological vascular changes which occur in severe dengue disease. In particular, their expression of Fc receptors makes them powerful amplifiers of DENV replication as well as of virus-induced innate immune factors some of which act directly on vascular endothelium and others of which regulate the extent of virus replication.

\section{Abbreviations}

CCL: Chemokine (C-C motif) ligand; CMP: Common myeloid progenitor; CXCL: Chemokine (C-X-C motif) ligand; DENV: Dengue virus; DF: Dengue fever; DHF: Dengue hemorrhagic fever (DHF); dsRNA: double-stranded ribonucleic acid; DSS: Dengue shock syndrome; elF: eukaryotic initiation factor; GMP: Granulocyte/monocyte progenitor; IFN: Interferon; IL: Interleukin; MIF: Macrophage migration inhibitory factor; MMP: Matrix metalloproteinase; NK: Natural killer; NS1: Non-structural protein 1; PKR: Protein kinase R: TLR: Toll-like receptor; TNF: Tumor necrosis factor 


\section{Acknowledgements}

The authors gratefully acknowledge the contributions of numerous colleagues and collaborators, listed in previous publications.

\section{Funding}

Work performed in the authors' laboratories was supported by Grants from the Ministry of Science and Technology, Taiwan and the Canadian Institutes of Health Research.

\section{Availability of data and materials} not applicable.

\section{Authors' contributions}

All authors discussed and designed the concept. RA, SWW, BAWH, YSL, WYC and YH collected information, prepared and wrote the manuscript. All authors read and approved the final manuscript.

\section{Ethics approval and consent to participate}

not applicable.

\section{Consent for publication}

not applicable.

\section{Competing interests}

The authors declare that they have no competing interests.

\section{Publisher's Note}

Springer Nature remains neutral with regard to jurisdictional claims in published maps and institutional affiliations.

\section{Author details \\ ${ }^{1}$ School of Medicine, College of Medicine, I-Shou University, Kaohsiung, Taiwan. ${ }^{2}$ Graduate Institute of Immunology, College of Medicine, National Taiwan University, Taipei, Taiwan. ${ }^{3}$ Department of Microbiology and Immunology, College of Medicine, National Cheng Kung University, Tainan, Taiwan. ${ }^{4}$ Center of Infectious Disease and Signaling Research, National Cheng Kung University, Tainan, Taiwan. ${ }^{5}$ Department of Microbiology \& Immunology, Dalhousie University, Halifax, NS B3H 4R2, Canada. ${ }^{6}$ Canadian Center for Vaccinology, Dalhousie University, Halifax, Canada.}

\section{Received: 24 May 2018 Accepted: 24 October 2018}

\section{Published online: 08 November 2018}

\section{References}

1. Bhatt S, Gething PW, Brady OJ, Messina JP, Farlow AW, Moyes CL, et al. The global distribution and burden of denque. Nature. 2013:496:504-7.

2. Rothman AL. Dengue: defining protective versus pathologic immunity. J Clin Invest. 2004;113:946-51.

3. Halstead SB. Dengue. Lancet. 2007;370:1644-52.

4. Guzman MG, Harris E. Dengue. Lancet. 2015;385:453-65.

5. Guy B, Lang J, Saville M, Jackson N. Vaccination against dengue: challenges and current developments. Annu Rev Med. 2016:67:387-404.

6. Vannice KS, Durbin A, Hombach J. Status of vaccine research and development of vaccines for dengue. Vaccine. 2016;34:2934-8.

7. Elong Ngono A, Shresta S. Immune response to denque and zika. Annu Rev Immunol. 2018;36:279-308

8. Malavige GN, Ogg GS. Pathogenesis of vascular leak in dengue virus infection. Immunology. 2017;151:261-9.

9. Voehringer D. Protective and pathological roles of mast cells and basophils. Nat Rev Immunol. 2013;13:362-75.

10. Dahlin JS, Hallgren J. Mast cell progenitors: origin, development and migration to tissues. Mol Immunol. 2015;63:9-17.

11. Halstead SB, O'Rourke EJ. Dengue viruses and mononuclear phagocytes. I. Infection enhancement by non-neutralizing antibody. J Exp Med. 1977;146: 201-17

12. Chen YC, Wang SY. Activation of terminally differentiated human monocytes/macrophages by dengue virus: productive infection, hierarchical production of innate cytokines and chemokines, and the synergistic effect of lipopolysaccharide. J Virol. 2002;76:9877-87.

13. Kou Z, Quinn M, Chen H, Rodrigo WW, Rose RC, Schlesinger JJ, et al. Monocytes, but not T or B cells, are the principal target cells for dengue virus (DV) infection among human peripheral blood mononuclear cells. J Med Virol. 2008;80:134-46.

14. Durbin AP, Vargas MJ, Wanionek K, Hammond SN, Gordon A, Rocha C, et al. Phenotyping of peripheral blood mononuclear cells during acute dengue illness demonstrates infection and increased activation of monocytes in severe cases compared to classic dengue fever. Virology. 2008;376:429-35.

15. Halstead SB, Chow JS, Marchette NJ. Immunological enhancement of dengue virus replication. Nat New Biol. 1973;243:24-6.

16. Halstead SB, O'Rourke EJ. Antibody-enhanced dengue virus infection in primate leukocytes. Nature. 1977;265:739-41.

17. Xavier-Carvalho C, Cardoso CC, de Souza Kehdy F, Pacheco AG, Moraes MO. Host genetics and dengue fever. Infect Genet Evol. 2017;56:99-110.

18. Halstead SB. Dengue antibody-dependent enhancement: knowns and unknowns. Microbiol Spectr. 2014;2:AID-0022-2014.

19. Ubol S, Phuklia W, Kalayanarooj S, Modhiran N. Mechanisms of immune evasion induced by a complex of dengue virus and preexisting enhancing antibodies. J Infect Dis. 2010;201:923-35.

20. Kou Z, Lim JY, Beltramello M, Quinn M, Chen H, Liu S, et al. Human antibodies against dengue enhance denque viral infectivity without suppressing type I interferon secretion in primary human monocytes. Virology. 2011:410:240-7.

21. O'Sullivan MA, Killen HM. The differentiation state of monocytic cells affects their susceptibility to infection and the effects of infection by dengue virus. J Gen Virol. 1994;75:2387-92.

22. Kwissa M, Nakaya HI, Onlamoon N, Wrammert J, Villinger F, Perng GC, et al. Dengue virus infection induces expansion of a CD14(+)CD16(+) monocyte population that stimulates plasmablast differentiation. Cell Host Microbe. 2014;16:115-27

23. Saha P, Geissmann F. Toward a functional characterization of blood monocytes. Immunol Cell Biol. 2011;89:2-4.

24. Ziegler-Heitbrock L, Hofer TP. Toward a refined definition of monocyte subsets. Front Immunol. 2013:4:23.

25. Duyen HTL, Cerny D, Trung DT, Pang J, Velumani S, Toh YX, et al. Skin dendritic cell and $T$ cell activation associated with dengue shock syndrome. Sci Rep. 2017;7:14224.

26. Anderson R, Wang S, Osiowy C, Issekutz AC. Activation of endothelial cells via antibody-enhanced dengue virus infection of peripheral blood monocytes. J Virol. 1997:71:4226-32.

27. Bethell DB, Flobbe K, Cao XT, Day NP, Pham TP, Buurman WA, et al. Pathophysiologic and prognostic role of cytokines in dengue hemorrhagic fever. J Infect Dis. 1998;177:778-82.

28. Hober D, Poli L, Roblin B, Gestas P, Chungue E, Granic G, et al. Serum levels of tumor necrosis factor-alpha (TNF-alpha), interleukin-6 (IL-6), and interleukin-1 beta (IL-1 beta) in dengue-infected patients. Am J Trop Med Hyg. 1993;48:324-31

29. Yadav M, Kamath KR, lyngkaran N, Sinniah M. Dengue haemorrhagic fever and dengue shock syndrome: are they tumour necrosis factor-mediated disorders? FEMS Microbiollmmunol. 1991;89:45-50.

30. Chen HC, Hofman FM, Kung JT, Lin YD, Wu-Hsieh BA. Both virus and tumor necrosis factor alpha are critical for endothelium damage in a mouse model of dengue virus-induced hemorrhage. J Virol. 2007:81:5518-26.

31. Chen HR, Chuang YC, Lin YS, Liu HS, Liu CC, Perng GC, et al. Dengue virus nonstructural protein 1 induces vascular leakage through macrophage migration inhibitory factor and autophagy. PLoS Negl Trop Dis. 2016;10:e0004828.

32. Tang TH, Alonso S, Ng LF, Thein TL, Pang VJ, Leo YS, et al. Increased serum hyaluronic acid and heparan sulfate in dengue fever: association with plasma leakage and disease severity. Sci Rep. 2017;7:46191.

33. Trugilho MRO, Hottz ED, Brunoro GVF, Teixeira-Ferreira A, Carvalho PC, Salazar GA, et al. Platelet proteome reveals novel pathways of platelet activation and platelet-mediated immunoregulation in dengue. PLoS Pathog. 2017;13:e1006385

34. Hottz ED, Medeiros-de-Moraes IM, Vieira-de-Abreu A, de Assis EF, Vals-de-Souza $\mathrm{R}$, Castro-Faria-Neto HC, et al. Platelet activation and apoptosis modulate monocyte inflammatory responses in denque. J Immunol. 2014;193:1864-72.

35. Costa W, Ye W, Chen Q, Teixeira MM, Preiser P, Ooi EE, et al. Dengue virusinfected dendritic cells, but not monocytes, activate natural killer cells through a contact-dependent mechanism involving adhesion molecules. MBio. 2017:8:e00741

36. Gandini M, Petitinga-Paiva F, Marinho CF, Correa G, De Oliveira-Pinto LM, de Souza $L$, et al. Dengue virus induces NK cell activation through TRAlL expression during infection. Mediat Inflamm. 2017;2017:5649214. 
37. Kwan $W H$, Navarro-Sanchez $E$, Dumortier $H$, Decossas $M$, Vachon $H$, dos Santos FB, et al. Dermal-type macrophages expressing CD209/DC-SIGN show inherent resistance to dengue virus growth. PLoS Negl Trop Dis. 2008;2:e311.

38. Cerny D, Haniffa M, Shin A, Bigliardi P, Tan BK, Lee B, et al. Selective susceptibility of human skin antigen presenting cells to productive dengue virus infection. PLoS Pathog. 2014;10:e1004548.

39. Schmid MA, Harris E. Monocyte recruitment to the dermis and differentiation to dendritic cells increases the targets for dengue virus replication. PLoS Pathog. 2014;10:e1004541.

40. Tamoutounour S, Guilliams M, Montanana Sanchis F, Liu H, Terhorst D, Malosse C, et al. Origins and functional specialization of macrophages and of conventional and monocyte-derived dendritic cells in mouse skin. Immunity. 2013;39:925-38.

41. Myint KS, Endy TP, Mongkolsirichaikul D, Manomuth C, Kalayanarooj S, Vaughn DW, et al. Cellular immune activation in children with acute dengue virus infections is modulated by apoptosis. J Infect Dis. 2006;194:600-7.

42. Arias J, Valero N, Mosquera J, Montiel M, Reyes E, Larreal Y, et al. Increased expression of cytokines, soluble cytokine receptors, soluble apoptosis ligand and apoptosis in dengue. Virology. 2014:452-453:42-51.

43. Klomporn P, Panyasrivanit M, Wikan N, Smith DR. Dengue infection of monocytic cells activates ER stress pathways, but apoptosis is induced through both extrinsic and intrinsic pathways. Virology. 2011;409:189-97.

44. Levy A, Valero N, Espina LM, Anez G, Arias J, Mosquera J. Increment of interleukin 6, tumour necrosis factor alpha, nitric oxide, C-reactive protein and apoptosis in dengue. Trans R Soc Trop Med Hyg. 2010;104:16-23.

45. Espina LM, Valero NJ, Hernandez JM, Mosquera JA. Increased apoptosis and expression of tumor necrosis factor-alpha caused by infection of cultured human monocytes with dengue virus. Am J Trop Med Hyg. 2003;68:48-53.

46. Torrentes-Carvalho A, Azeredo EL, Reis SR, Miranda AS, Gandini M, Barbosa $L S$, et al. Dengue-2 infection and the induction of apoptosis in human primary monocytes. Mem Inst Oswaldo Cruz. 2009;104:1091-9.

47. Tan TY, Chu JJ. Dengue virus-infected human monocytes trigger late activation of caspase-1, which mediates pro-inflammatory IL-1 beta secretion and pyroptosis. J Gen Virol. 2013;94:2215-20.

48. Jessie K, Fong MY, Devi S, Lam SK, Wong KT. Localization of dengue virus in naturally infected human tissues, by immunohistochemistry and in situ hybridization. J Infect Dis. 2004;189:1411-8.

49. Balsitis SJ, Coloma J, Castro G, Alava A, Flores D, McKerrow JH, et al. Tropism of dengue virus in mice and humans defined by viral nonstructural protein 3-specific immunostaining. Am J Trop Med Hyg. 2009:80:416-24.

50. Blackley S, Kou Z, Chen H, Quinn M, Rose RC, Schlesinger JJ, et al. Primary human splenic macrophages, but not T or B cells, are the principal target cells for dengue virus infection in vitro. J Virol. 2007;81:13325-34.

51. Miller JL, de Wet BJ, Martinez-Pomares L, Radcliffe CM, Dwek RA, Rudd PM, et al. The mannose receptor mediates dengue virus infection of macrophages. PLoS Pathog. 2008;4:e17.

52. Schaeffer E, Flacher V, Papageorgiou V, Decossas M, Fauny JD, Kramer $M$, et al. Dermal CD14(+) dendritic cell and macrophage infection by dengue virus is stimulated by Interleukin-4. J Invest Dermatol. 2015; 135:1743-51.

53. Stein M, Keshav S, Harris N, Gordon S. Interleukin 4 potently enhances murine macrophage mannose receptor activity: a marker of alternative immunologic macrophage activation. J Exp Med. 1992;176:287-92.

54. Chen ST, Lin YL, Huang MT, Wu MF, Cheng SC, Lei HY, et al. CLEC5A is critical for dengue-virus-induced lethal disease. Nature. 2008:453:672-6.

55. Wu MF, Chen ST, Yang AH, Lin WW, Lin YL, Chen NJ, et al. CLEC5A is critical for dengue virus-induced inflammasome activation in human macrophages. Blood. 2013;121:95-106.

56. Kyle $J$, Beatty PR, Harris E. Dengue virus infects macrophages and dendritic cells in a mouse model of infection. J Infect Dis. 2007;195:1808-17.

57. Prestwood TR, May MM, Plummer EM, Morar MM, Yauch LE, Shresta S. Trafficking and replication patterns reveal splenic macrophages as major targets of dengue virus in mice. J Virol. 2012;86:12138-47.

58. Yen YT, Chen HC, Lin YD, Shieh CC, Wu-Hsieh BA. Enhancement by tumor necrosis factor alpha of dengue virus-induced endothelial cell production of reactive nitrogen and oxygen species is key to hemorrhage development. J Virol. 2008;82:12312-24.

59. Povoa TF, Oliveira ER, Basilio-de-Oliveira CA, Nuovo GJ, Chagas VL, Salomao $N G$, et al. Peripheral organs of dengue fatal cases present strong proinflammatory response with participation of IFN-gamma-, TNF-alpha- and RANTES-producing cells. PLoS One. 2016;11:e0168973.
60. Hober D, Delannoy AS, Benyoucef S, De GD, Wattre P. High levels of sTNFR p75 and TNF alpha in dengue-infected patients. Microbiol Immunol. 1996:40:569-73.

61. Brown MG, Hermann LL, Issekutz AC, Marshall JS, Rowter D, Al-Afif A, et al. Dengue virus infection of mast cells triggers endothelial cell activation. J Virol. 2011:85:1145-50

62. Marianneau P, Steffan AM, Royer C, Drouet MT, Jaeck D, Kirn A, et al. Infection of primary cultures of human Kupffer cells by dengue virus: no viral progeny synthesis, but cytokine production is evident. J Virol. 1999;73: 5201-6.

63. Aye KS, Charngkaew K, Win N, Wai KZ, Moe K, Punyadee N, et al. Pathologic highlights of dengue hemorrhagic fever in 13 autopsy cases from Myanmar. Hum Pathol. 2014:45:1221-33.

64. Marianneau P, Flamand M, Deubel V, Despres P. Apoptotic cell death in response to dengue virus infection: the pathogenesis of dengue haemorrhagic fever revisited. Clin Diagn Virol. 1998;10:113-9.

65. Lin JC, Lin SC, Chen WY, Yen YT, Lai CW, Tao MH, et al. Dengue vira protease interaction with NF-kappaB inhibitor alpha/beta results in endothelial cell apoptosis and hemorrhage development. J Immunol. 2014;193:1258-67

66. Marshall JS. Mast-cell responses to pathogens. Nat Rev Immunol. 2004:4:787-99.

67. Dawicki W, Marshall JS. New and emerging roles for mast cells in host defence. Curr Opin Immunol. 2007;19:31-8.

68. Metz M, Siebenhaar F, Maurer M. Mast cell functions in the innate skin immune system. Immunobiology. 2008;213:251-60.

69. Galli SJ, Tsai M. Mast cells: versatile regulators of inflammation, tissue remodeling, host defense and homeostasis. J Dermatol Sci. 2008;49:7-19.

70. Selye H. Mast cells and necrosis. Science. 1966;152:1371-2.

71. Wiesner-Menzel L, Schulz B, Vakilzadeh F, Czarnetzki BM. Electron microscopical evidence for a direct contact between nerve fibres and mast cells. Acta Derm Venereol. 1981:61:465-9.

72. Sperr WR, Bankl HC, Mundigler G, Klappacher G, Grossschmidt K, Agis H, et al. The human cardiac mast cell: localization, isolation, phenotype, and functional characterization. Blood. 1994;84:3876-84.

73. Guo CB, Kagey-Sobotka A, Lichtenstein LM, Bochner BS. Immunophenotyping and functional analysis of purified human uterine mast cells. Blood. 1992;79:708-12.

74. Okayama Y, Hagaman DD, Woolhiser M, Metcalfe DD. Further characterization of FcgammaRII and FcgammaRIII expression by cultured human mast cells. Int Arch Allergy Immunol. 2001;124:155-7.

75. Okayama Y, Kirshenbaum AS, Metcalfe DD. Expression of a functional highaffinity lgG receptor, fc gamma Rl, on human mast cells: up-regulation by IFN-gamma. J Immunol. 2000;164:4332-9.

76. Okayama Y, Hagaman DD. Metcalfe DD. A comparison of mediators released or generated by IFN-gamma-treated human mast cells following aggregation of fc gamma RI or fc epsilon RI. J Immunol. 2001;166:4705-12.

77. Wedi B, Lewrick H, Butterfield JH, Kapp A. Human HMC-1 mast cells exclusively express the fc gamma RII subtype of lgG receptor. Arch Dermatol Res. 1996;289:21-7.

78. Wu SJ, Grouard-Vogel G, Sun W, Mascola JR, Brachtel E, Putvatana R, et al. Human skin Langerhans cells are targets of dengue virus infection. Nat Med. 2000:6:816-20.

79. St John AL, Rathore AP, Yap H, Ng ML, Metcalfe DD, Vasudevan SG, et al. Immune surveillance by mast cells during denque infection promotes natural killer (NK) and NKT-cell recruitment and viral clearance. Proc Natl Acad Sci U S A. 2011;108:9190-5.

80. Tuchinda M, Dhorranintra B, Tuchinda P. Histamine content in 24-hour urine in patients with dengue haemorrhagic fever. Southeast Asian J Trop Med Public Health. 1977:8:80-3.

81. Phan DT, Ha NT, Thuc LT, Diet NH, Phu LV, Ninh LY, et al. Some changes in immunity and blood in relation to clinical states of dengue hemorrhagic fever patients in Vietnam. Haematologia (Budap). 1991;24:13-21.

82. Furuta T, Murao LA, Lan NT, Huy NT, Huong VT, Thuy TT, et al. Association of mast cell-derived VEGF and proteases in dengue shock syndrome. PLoS Negl Trop Dis. 2012;6:e1505.

83. St John AL, Rathore AP, Raghavan B, Ng ML, Abraham SN. Contributions of mast cells and vasoactive products, leukotrienes and chymase, to dengue virus-induced vascular leakage. elife. 2013;2:e00481.

84. King CA, Anderson R, Marshall JS. Dengue virus selectively induces human mast cell chemokine production. J Virol. 2002;76:8408-19. 
85. Brown MG, MCAlpine SM, Huang YY, Haidl ID, Al-Afif A, Marshall JS, et al. RNA sensors enable human mast cell anti-viral chemokine production and IFN-mediated protection in response to antibody-enhanced dengue virus infection. PLoS One. 2012;7:e34055

86. King CA, Marshall JS, Alshurafa $H$, Anderson R. Release of vasoactive cytokines by antibody-enhanced dengue virus infection of a human mast cell/basophil line. J Virol. 2000;74:7146-50.

87. Brown MG, King CA, Sherren C, Marshall JS, Anderson R. A dominant role for FcgammaRII in antibody-enhanced dengue virus infection of human mast cells and associated CCL5 release. J Leukoc Biol. 2006;80:1242-50.

88. Orinska Z, Bulanova E, Budagian V, Metz M, Maurer M, Bulfone-Paus S. TLR3induced activation of mast cells modulates CD8+ T-cell recruitment. Blood. 2005;106:978-87.

89. Kulka M, Alexopoulou L, Flavell RA, Metcalfe DD. Activation of mast cells by double-stranded RNA: evidence for activation through toll-like receptor 3. J Allergy Clin Immunol. 2004;114:174-82.

90. Perez AB, Garcia G, Sierra B, Alvarez M, Vazquez S, Cabrera MV, et al. IL-10 levels in dengue patients: some findings from the exceptional epidemiological conditions in Cuba. J Med Virol. 2004;73:230-4.

91. Cui L, Lee YH, Thein TL, Fang J, Pang J, Ooi EE, et al. Serum metabolomics reveals serotonin as a predictor of severe dengue in the early phase of dengue fever. PLoS Negl Trop Dis. 2016;10:e0004607.

92. van de Weg CA, Pannuti CS, de Araujo ES, van den Ham HJ, Andeweg AC, Boas LS, et al. Microbial translocation is associated with extensive immune activation in dengue virus infected patients with severe disease. PLoS Negl Trop Dis. 2013;7:e2236.

93. Bozza FA, Cruz OG, Zagne SM, Azeredo EL, Nogueira RM, Assis EF, et al. Multiplex cytokine profile from dengue patients: MIP-1beta and IFN-gamma as predictive factors for severity. BMC Infect Dis. 2008;8:86.

94. Wagoner J, Austin M, Green J, Imaizumi T, Casola A, Brasier A, et al. Regulation of CXCL-8 (interleukin-8) induction by double-stranded RNA signaling pathways during hepatitis C virus infection. J Virol. 2007;81:309-18.

95. Yoshida H, Imaizumi T, Lee SJ, Tanji K, Sakaki H, Matsumiya T, et al. Retinoic acid-inducible gene-I mediates RANTES/CCL5 expression in U373MG human astrocytoma cells stimulated with double-stranded RNA. Neurosci Res. 2007:58:199-206.

96. Diamond MS, Harris E. Interferon inhibits dengue virus infection by preventing translation of viral RNA through a PKR-independent mechanism. Virology. 2001;289:297-311.

97. Matsushima H, Yamada N, Matsue H, Shimada S. TLR3-, TLR7-, and TLR9mediated production of proinflammatory cytokines and chemokines from murine connective tissue type skin-derived mast cells but not from bone marrow-derived mast cells. J Immunol. 2004;173:531-41.

98. McCurdy JD, Olynych TJ, Maher LH, Marshall JS. Cutting edge: distinct tolllike receptor 2 activators selectively induce different classes of mediator production from human mast cells. J Immunol. 2003;170:1625-9.

99. Kulka M, Metcalfe DD. TLR3 activation inhibits human mast cell attachment to fibronectin and vitronectin. Mol Immunol. 2006:43:1579-86.

100. Bonini S, Micera A, lovieno A, Lambiase A, Bonini S. Expression of toll-like receptors in healthy and allergic conjunctiva. Ophthalmology. 2005;112: 1528-34.

101. Burke SM, Issekutz TB, Mohan K, Lee PW, Shmulevitz M, Marshall JS. Human mast cell activation with virus-associated stimuli leads to the selective chemotaxis of natural killer cells by a CXCL8-dependent mechanism. Blood. 2008;111:5467-76.

102. Munoz-Jordan JL, Fredericksen BL. How flaviviruses activate and suppress the interferon response. Viruses. 2010;2:676-91.

103. Nasirudeen AM, Wong HH, Thien P, Xu S, Lam KP, Liu DX. RIG-I, MDA5 and TLR3 synergistically play an important role in restriction of dengue virus infection. PLoS Negl Trop Dis. 2011;5:e926.

104. Qin CF, Zhao H, Liu ZY, Jiang T, Deng YQ, Yu XD, et al. Retinoic acid inducible gene-I and melanoma differentiation-associated gene 5 are induced but not essential for dengue virus induced type I interferon response. Mol Biol Rep. 2011;38:3867-73.

105. Chu YT, Wan SW, Anderson R, Lin YS. Mast cell-macrophage dynamics in modulation of dengue virus infection in skin. Immunology. 2015;146:163-72.

106. Tissera H, Rathore APS, Leong WY, Pike BL, Warkentien TE, Farouk FS, et al. Chymase level is a predictive biomarker of dengue hemorrhagic fever in pediatric and adult patients. J Infect Dis. 2017;216:1112-21.
107. Syenina A, Jagaraj CJ, Aman SA, Sridharan A, St John AL. Dengue vascular leakage is augmented by mast cell degranulation mediated by immunoglobulin Fcgamma receptors. elife. 2015;4:e05291.

108. Morrison J, Rathore APS, Mantri CK, Aman SAB, Nishida A, St John AL Transcriptional profiling confirms the therapeutic effects of mast cell stabilization in a dengue disease model. J Virol. 2017;91:e00617.

109. Chu YT, Wan SW, Chang YC, Lee CK, Wu-Hsieh BA, Anderson R, et al. Antibodies against nonstructural protein 1 protect mice from dengue virusinduced mast cell activation. Lab Investig. 2017;97:602-14.

110. Brown MG, Huang YY, Marshall JS, King CA, Hoskin DW, Anderson R. Dramatic caspase-dependent apoptosis in antibody-enhanced dengue virus infection of human mast cells. J Leukoc Biol. 2009;85:71-80.
Ready to submit your research? Choose BMC and benefit from:

- fast, convenient online submission

- thorough peer review by experienced researchers in your field

- rapid publication on acceptance

- support for research data, including large and complex data types

- gold Open Access which fosters wider collaboration and increased citations

- maximum visibility for your research: over $100 \mathrm{M}$ website views per year

At BMC, research is always in progress.

Learn more biomedcentral.com/submissions 